\title{
Entrevista a un cavernísofo ${ }^{1}$
}

\author{
Interview with a "cavernisofo" \\ JUAN A. NEGRETE - ALEJANDRO ROJAS
}

\begin{abstract}
RESUMEN
Entrevista a Juan. A. Negrete, premio anual 2014 a la promoción de la filosofía y la cultura en Málaga. El premio se hace extensivo a la red de blogs: Cavernisofía, Cavernética y Cavernisofíasegundaplanta.

\author{
PALABRAS CLAVE \\ CAVERNISOFÍA, FILOSOFÍA, DIÁLOGO
}

\begin{abstract}
Interview with Juan. A. Negrete, annual prize 2014 to the promotion of the philosophy and the culture in Málaga. The award is extended to the network of blogs: Cavernisofía, Cavernética and Cavernisofíasegundaplanta.

KEY WORDS

CAVERNISOFÍA, PHILOSOPHY, DIALOG
\end{abstract}

Claridades. Revista de filosofía, 7 (2015), pp 129-135

ISSN: 1889-6855 ISSN-e: 1989-3787 Dl.: PM 1131-2009

Asociación para la promoción de la Filosofía y la Cultura (FICUM)

\footnotetext{
${ }^{1}$ Esta entrevista fue publicada originariamente en el portal FILOSOFÍA NOTICIAS de FICUM el 2 de julio de 2014.
} 
El FilÓsofo JuAn A. NEgRETE AlCudia nació en 1969 en Madrid, estudió Filología Clásica en la Universidad Complutense. Es profesor de Filosofía en el IES Pascual Carrión de Sax (Alicante) desde 2003-4. Ha publicado tres libros, Diálogos de Filosofía, Diálogos de Educación (2011 y 2013, Editorial Manuscritos) y, junto a Elena Díez de la Cortina, La filosofía de Platón, libro multi-táctil para iPad destinado a estudiantes, y diversos artículos. Es también músico, y actualmente forma parte del trío BONAVAL, de música folk "mediterránea". Además de los blogs de filosofía para bachillerato y cuarto de la ESO, cavernisofía, cavernética y cavernisofía-segunda-planta, mantiene dos blogs "serios" de filosofía: www.dialecticayanalogia.blogspot.com y www.biendeverdad.blogspot.com.

Alejandro Rojas- Juan Antonio, me gustaría empezar preguntándote por los habitantes de vuestra red de cavernas, los cavernísofos. ¿Quiénes son y que hace falta para ser cavernísofos?

Juan A. Negrete- Bien: como parece inevitable para un cavernísofo, tengo que darte una respuesta paradójica. Por una parte, nuestra red de cavernas está habitada por una particular serie de personajes de varias especies, a saber: los espectros cavernísofos de los grandes filósofos de la Historia (Heráclito, Anaximandro, Protágoras, Sócrates, Platón, Aristóteles, Diógenes... y así hasta Nietzsche o Wittgenstein, por ejemplo); después, alumnos, alumnas y profesor de cavernisofía y su red de pasadizos, conectados además con los antros de nuestro amigo Víctor Bermúdez (Filosofía y Ciudadanía para cavernícolas, en blogpspot); y, también, por todos aquellos que, desde diferentes puntos del universo, nos visitáis y dejáis vuestro más o menos locuaz o silencioso pero siempre luminífero rastro. Pero -he aquí el otro cuerno de la respuesta-, en realidad no hay que hacer nada para ser cavernísofo; lo que es más, es imposible dejar de serlo, al menos en vida, puesto que la cavernisofía es la condición "natural" de todas las almas que, como cuenta el Sócrates de Platón en el Fedón, habitamos los diversos antros de la Tierra auténtica, comunicados por el fluido universal de la consciencia y el lenguaje. Quien pretendiese negar ser cavernísofo, estaría, por eso mismo, mostrando claramente que lo es. Un cavernísofo es, en definitiva, quien cesa por un momento en su frenética faena de solucionar los problemas que surgen en la vida y se plantea radicalmente el problema de la vida. Y ¿quién puede o quiere pri-

Claridades. Revista de filosofía 7 (2015) 
varse de eso? De modo que nuestra bienvenida a Cavernisofía dice: "bienvenido a donde ya estás". Así, cavernisofía es un poco como todos los lugares cavernísofos e incluso todos los seres: totalmente concreto y particular, pero, a la vez, universal y abierto a todos. "Para todos y para nadie", que dijo nuestro ilustre cavernísofo Federico.

Además - esto es una primicia- en breve estos pasadizos irrigarán también Radio 5 de Radio Nacional de España, mediante un programa titulado "Diálogos en la caverna", mucho de cuyo material procede de nuestros blogs y los de Víctor Bermúdez.

AR.- ¡Excelente noticia! Lo cierto es que los diálogos que aparecen en vuestras rutas son geniales y divertidos, y merecen tener ese espacio en la Radio Nacional. Recrear diálogos entre Nietzsche y Kant, Platón y Nietzsche, Kant y Platón... permite un acercamiento realmente simpático, ilustrativo, ameno y diferente a la historia de la filosofía. Recuerdo con especial agrado el fantástico pleito a la razón a propósito de la filosofía kantiana. Ofrecéis un acercamiento distinto al que nos tienen acostumbrados otros espacios y ágoras filosóficos. Por eso, aunque, como dices, todos seamos un poco cavernísofos, hay algo fresco y diferente en vuestras rutas que hacen de vuestro mundo cavernísofo algo muy especial. Permíteme reformular este comentario en forma de pregunta: ¿qué dirías que hace a cavernisofía un poco diferente a otros antros filosóficos?

$J A N$.- Bueno, aunque, como bien dices, todos los que nos dedicamos a esto con nuestras ágoras, practicamos la misma espeleosofía, y nosotros nos sentimos a gusto en todas ellas, quizás el rasgo más distintivo de cavernisofía sea, como indicas, que nos entregamos al aspecto más lúdico y teatral del asunto, sin querer perder, por ello, un ápice de "seriedad", en el buen sentido de guardar el mayor respeto por las ideas y sus autores. Es más, quizás así, dramatizándolas y encarnándolos, les seamos más "fieles" que mediante el texto más aséptico. Ya decía el profundo y loco cavernísofo Heráclito que el propio cosmos es el juego de un niño; también nuestro patrón Platón (porque estas cavernas, lo reconocemos, son bastante platónicas) recomienda educar jugando y él mismo no hace más que jugar en sus diálogos y mitos; y la misma alma gemela de Platón, Nietzsche (nuestro otro gran patrón) dijo que él solo creería en un dios que supiese bailar. ¿Por qué? Bien: un juego es una actividad de la inteli- 
gencia que tiene su fin en sí misma. Y eso precisamente creemos que hay que procurar de la filosofía, y de la educación en general, que (a diferencia de la instrucción), inmediatamente no sirven para nada, más que para intentar conocerse (o desconocerse) a sí mismo y ser feliz en el propio acto de intentarlo; aunque, después, y casi como sin quererlo, sirven para todo, o sea, para preguntárselo críticamente todo. Hay que asumir que la cavernisofía es una locura respecto de la normalidad normal, y que eso la hace tan imposible como necesaria.

AR.- A propósito de esos diálogos que recreas magistralmente recuperando con éxito el estilo originario con el que se pone en escena por primera vez la filosofía en acción, es decir recuperando el estilo de aquellos diálogos platónicos en los que el protagonismo recaía sobre tesis que rivalizaban entre ellas y donde, como nos recuerda Luciano de Samósata en sus Relatos verídicos, "el único ausente era Platón" (que nunca hablaba en primera persona), quiero preguntarte acerca de tu "ausencia" en esos diálogos.

$J A N$.- Esa me parece una pregunta también muy interesante, y en la que, lo confieso, no he reflexionado hasta ahora demasiado por lo que se refiere al blog. Siempre he disfrutado mucho (también sufrido) leyendo los diálogos de Platón, iy los de Luciano, por cierto!, y después he disfrutado mucho también escribiendo en esa forma (los dos libros que he publicado en papel se titulan Diálogos de Filosofía y Diálogos de Educación, aunque no tienen el carácter divulgativo de caverniso-fía). Y he pensado a veces, pero más bien en abstracto, acerca del por qué el diálogo es tan adecuado a la filosofía. Y creo que la razón está en algo que ya se ha dicho a veces pero quizás no se ha asumido lo suficiente: la filosofía es dialéctica (y esta es la misma palabra que 'diálogo'), es decir, los asuntos que trata nunca tienen una solución limpiamente unilateral, sino que siempre implican a su otro, y "la verdad" está, más bien, en el todo. Este es, por una parte, el escándalo de la Filosofía (no produce acuerdo unánime, "no hay nada lo suficientemente loco como para que no lo haya sostenido algún filósofo" -dijo alguien-), pero yo creo que es también su virtud: ¿recuerdas algún tema interesante en el que haya una solución clara y unilateral? Ni en arte, ni en política ni en la vida cotidiana existe algo así, creo yo. Desde luego, una de las cosas que más asombra a los alumnos, cuando tenemos éxito en nuestro enseñar a filosofar, es que

Claridades. Revista de filosofía 7 (2015) 
todas las filosofías le parecen la verdadera, o al menos muy razonables, cuando están dentro de ella, y un evidente error e incluso un absurdo cuando están en otro filósofo. Como profesor de filosofía, siempre me he propuesto eso, es decir, dejarme poseer lo más posible por cada pensador hasta hacerlo plenamente convincente (para mí en primer lugar: me vuelvo casi literalmente nietzscheano por primavera, tras un otoño platónico y un frío pero sano invierno cartesiano), y eso es llevado al límite en el diálogo, donde ellos son confrontados directamente y resultan tan convincentes como errados en el mismo momento: eso es, creo yo, lo que me lleva a esa falta de reverencia de poner en su boca palabras mías (y algún alumno, en alguna ocasión, se ha confundido y creído que eran palabras del "verdadero" autor que leíamos). No obstante, a la vez, quienes me conocen de cerca dicen que me ven en todos los personajes, por dispares que sean. Esto me parece bien, aunque ocurra sin haberlo pretendido: como te decía antes, creo que un cavernísofo tiene que ser a la vez todas las ideas y ninguna de ellas, imitando así al propio Logos que, según Heráclito, es uno y común, pero se manifiesta de maneras diferentes, como el fuego en los aromas según el incienso que quema.

AR.- Querido Juan Antonio, tu respuesta me parece realmente preciosa. Tanto que bien podría servir para cerrar esta breve entrevista de la que hemos aprendido tanto. Si acaso, te querría preguntar antes de finalizar por esos libros que has mencionado. ¿Qué nos esperaría de su lectura a los que nos hemos enganchado ya a la cavernisofía y nos sentimos plenamente cavernísofos?

$J A N$.- Muchas gracias por tus palabras, Alejandro, y por vuestra atención a cavernisofía-segunda-planta, que me ayuda a renovar las fuerzas para seguir jugando en ella con mis alumnos y con todos vosotros (jno descarto que aparezcáis en alguno de esos diálogos!). Respecto de mis libros, creo que, en cierto modo, podrían decepcionar a algunos de los cavernísofos que en el mundo han sido, pues no están pensados para un lector adolescente, aunque, desde luego, tampoco contra él (conozco algún profesor que los usa parcialmente en sus clases... -iy no soy yo, que, de hecho, no me conozco!-), sino que he intentado en ellos exponer mi propia visión filosófica y pedagógica. Eso sí, mediante el diálogo y sin apenas tecnicismos ni referencias muy específicas. Resumiendo mucho para que los lectores se puedan evitar su lectura o bien se vean obligados 
a ella-, lo que digo allí es que la filosofía, esto es, el pensamiento que quiere ir al fondo o "esencia" de las cosas, se vería obligada a reconocer, como decía antes, que la verdad no está en una posición unilateral (en el racionalismo o en el irracionalismo, en el espiritualismo o en el materialismo, en la ética de la justicia o en la del placer...), sino que cada una tiene sus virtudes y sus problemas o "aporías", de manera que el pensamiento está "condenado" (gustosamente condenado) a dar vueltas desde Platón a Nietzsche, por ejemplo, pasando por Aristóteles, Kant y todos los demás: es dialéctico. Pero también sostengo que, de entre los diversos caminos, no todos tienen exactamente el mismo peso o "valor", sino que la verdad está más del lado de lo racional que de lo irracional, de la unidad que de la multiplicidad, de la justicia que del interés particular: es analógica. A esto lo llamo también el "amor" en las cosas, que tiende, como decía Empédocles, a unir, pero no matando a la diferencia, sino haciéndola "armonía de los contrarios" en una unidad superior. La educación, por su parte, que concibo de manera socrática, tendría que ayudar a sacar de nosotros, razonando más que culpabilizando, eso para lo que tenemos una inclinación "natural" o esencial, o sea, comprender, amar..., y que, por ignorancia convertimos a menudo en incomprensión y odio. Cavernisofía no sueña, en el fondo, con otra cosa que con ser un no muy indigno ejercicio socrático.

AR.- Comparto desde luego el sueño de cavernisofía y su visión de la educación. Sin duda estamos ante una "ruta" que podría cambiar el modo como actualmente enfocamos la docencia en los centros de secundaria e incluso el modo como actualmente "se ve" la filosofía. Y no para que se conviertan en "buenas escuelas de filosofía", sino para que se permitan y fomenten los rayos o destellos de creación de los que dice Blas que (el personaje de uno de sus libros; juzguen ya vosotros qué hay o no de Juan Antonio aqui) "han existido de milagro, pese a la escuela". Esta cavernisofía es un viento de aire fresco que sin duda hará encender las brasas de una regenerada pasión por la filosofía que tanto cuesta encender entre los jóvenes, aburridos de tanta escuela y abrumados por la primacía actual de saberes aparentemente más prácticos que a menudo acaban por apagar esos destellos de los que hablaba "Blas". 
AR. - Muchas gracias querido Juan Antonio por compartir este tiempo y espacio con nosotros. Ha sido un verdadero placer pasarlo contigo. Espero que los posibles lectores hayan disfrutado tanto como yo.

J. A. NeGRETE es filósofo, músico, escritor y profesor en el IES Pascual Carrión.

Lineas de investigación:

La filosofía como dialéctico-analogía.

Publicaciones recientes:

- Diálogos de Educación, Manuscritos, Madrid, 2011.

Dirección electrónica: dialecticayanalogia@gmail.com

Claridades. Revista de filosofía 7 (2015) 